\title{
Klorheksidin uygulamasının bulk-fill ve nanofil kompozitlerin tamir bağlanma dayanımı üzerine etkisi
}

\author{
Vahti KIlıç(0000-0003-4653-3729) $^{\alpha}$, Feridun Hürmüzlü(0000-0003-2812-1835) ${ }^{\alpha}$ \\ Selcuk Dent J, 2018; 5: 225-232 (Doi: 10.15311/selcukdentj. 376364)
}

Başvuru Tarihi: 16 Ocak 2018 Yayına Kabul Tarihi: 17 Mayıs 2018

öz

Klorheksidin uygulamasının bulk-fill ve nanofil kompozitlerin tamir bağlanma dayanımı üzerine etkisi

Amaç: Bu çalışmanın amacı klorheksidin uygulamasının nanofil ve bulk-fill kompozitlerin tamir bağlanma dayanımı üzerine etkisini değerlendirmektir.

Gereç ve Yöntemler: Çalışmamızda kullanılmak üzere oluşturulan akrilik bloklar üzerinde 160 adet kavite hazırlandı. Kavitelerin yarısı nanofil kompozitlerle doldurulurken yarısı da bulk-fill kompozitlerle dolduruldu. Bütün örnekler 1 hafta $37^{\circ} \mathrm{C}$ distile suda bekletildikten sonra her restoratif materyalin örnekleri başlıca 2 deney grubuna ayrıldı. Grup 1'de örnekler 60 saniye klorheksidin uygulamasına maruz bırakıldı. Grup 2'deki örneklere ise bir uygulama yapılmadı (kontrol). Restoratif materyallerin uygun adezivleri her iki grupta ara tamir ajanı olarak uygulandı. Her gruptan örneklerin yarısı test öncesi termal siklusa ( 5000 siklus, 5-55 으, kalma süresi 30 saniye, transfer zamanı 15 saniye) maruz bırakıldı,diğer yarısı hemen teste alınarak tamir bağlanma dayanımı makaslama testi ile değerlendirildi. Deney gruplarının makaslama bağlanma dayanımı analiz etmek için çift yönlü ANOVA testi kullanıldı. Önemlilik seviyesi $(p<0.05)$ alındı. Bağlanma dayanımı testi sonrasında oluşan kırık tipleri optik loop ile incelendi ve gruplara ayrıldı. Kırık tipleri ayrıca Taramalı Elektron Mikroskobu ile görüntülendi.

Bulgular: Klorheksidin ve termal siklus uygulaması tamir bağlanma dayanımını anlamlı bir şekilde etkilememiştir $(p>0.05)$. Bulk-fill kompozitler daha düşük tamir bağlanma dayanımı göstermiştir. En yüksek bağlanma değeri Nanofil kompozitlerle 24 saat sonra kontrol grubunda elde edilirken en düşük değer klorheksidin uygulaması sonrası termal siklus yapılan Bulk-fill kompozitlerde bulunmuştur. Mix tip kırılmalar en fazla rastlanan tip kırılmalar olmuştur.

Sonuç: $\mathrm{Bu}$ in vitro çalışmanın sınırları içinde klorheksidin ve termal siklus ile uygulanan yaşlandırma metodu bulk-fill ve nanofil kompozitlerin tamir bağlanma dayanımını etkilememiştir.

\section{ANAHTAR KELIMELER}

Bulk-fill kompozit, klorheksidin, kompozit tamiri, nanofil kompozit, termal siklus

Son on yוl boyunca rezin kompozitler dental restorasyonlar için başlıca seçenek haline gelmişlerdir. Bu restoratif materyaller geleneksel olarak metakrilat teknolojisine dayalıdır ve daha iyi fiziksel özellikler ve optimal estetik görüntü elde etmek için devamlı olarak geliştirilmektedirler. ${ }^{1}$ Son zamanlarda geleneksel rezin kompozitlere alternatif olarak nanofil ve bulk-fill
ABSTRACT

The effect of chlorhexidin application on repair bond strenght of bulk-fill and nanofilled composites

Background: The aim of this study was to evaluate the effect of chlorhexidine application on the repair bond strength of nanofilled and bulk-fill composites.

Methods: 160 cavities were prepared on acrylic blocks. Half of the cavities were filled with nanofilled composites while half were filled with bulk-fill composites. All samples were stored in distilled water at $37^{\circ} \mathrm{C}$ for 1 week, and then samples of each restorative material were divided into 2 experimental groups. In Group 1, the samples were exposed to chlorhexidine for 60 seconds. In Group 2, there was no application (control). Appropriate adhesives of restorative materials were applied as intermediate repair agents in both groups. Half of the samples from each group were exposed to the pre-test thermal cycle (5000 cycles, 5$55 \circ \mathrm{C}$, residence time of 30 seconds, transfer time of 15 seconds); the other half was immediately taken to the test and evaluated by repair bond strength shear test. Two-way ANOVA test was used to analyze the shear bond strength of the experimental groups. Significance level $(p<0.05)$ was taken. The failure types formed after shear test were examined by optical loop and divided into groups. Failure types were also displayed with a Scanning Electron Microscope.

Results: Chlorhexidine and thermal cycling did not significantly affect repair bond strength ( $p>0.05$ ). Bulk-fill composites showed lower repair bond strength. Mix type failures are the most common type.

Conclusion: Chlorhexidine and additionally applied thermal cycle within the limits of this in vitro study did not affect the repair bond strength of bulk-fill and nanofilled composites.

\section{KEYWORDS}

Bulk-fill composite, chlorhexidine, composite repair, nanofilled composite, thermal cycle

kompozitler gibi yeni restoratif materyaller de geliştirilmiştir.

Nanofil kompozitler, çok iyi polisajlanabilen, aşınmaya dayanıkı ve estetik özelliklere sahip olup kolay uygulanan materyallerdir.,2,3 Hibrit kompozitlerde partikül büyüklüğü 8-30 $\mu \mathrm{m}$,

${ }^{\alpha}$ Cumhuriyet Üniversitesi Diş Hekimliği Fakültesi Restoratif Diş Tedavisi AD, Sivas 
mikrohibrit kompozitlerde partikül büyüklüğü 0.7-3.6 $\mu \mathrm{m}$ iken nano kompozitlerde 5-10nm'dir. ${ }^{4}$ Nanofil kompozit materyallerin organik yapısı diğer kompozit rezinlere benzer polimerik yapılardan meydana gelmektedir. İnorganik yapıyı meydana getiren partiküller ise; Silika nanodoldurucular (nanomer) ve nanomer grupları (nanocluster) kısımdan oluşmaktadır. Nanomer yapısı kümeleşmemiş partikülleri ifade eder ve kompozit rezinin organik yapısında ayrı ayrı bulunurlar. Nanomer grupları ise, 50 nm'den küçük nanomerlerin gevşek bağlar ile bir araya gelerek meydana getirdikleri yapılardır. ${ }^{5-7} \mathrm{Bu}$ gruplar tek bir birim gibi mekanik, optik ve termal özellikler gösterirler. ${ }^{8}$

Bulk fill kompozitler yeni nesil bir nanohibrit kompozit rezin türüdür. Üretici firmalara göre değişmekle beraber genel olarak; yiterbiyum triflorid, baryum cam, karmaoksit, proakrilat, zirkonyum/silika partikülleri içerirler. Bu partiküller, radyoopasiteyi artırarak ışık cihazının etkisinin materyalin daha derin bölgelerine ulaşabilmesini sağlamaktadır. Ayrıca kompozite mineye benzer bir şeffaflık vererek estetik üstünlük de sağlar. ${ }^{9,10}$ Bulk-fill kompozitler, kısa aktivasyon zamanı ve yeterli polimerizasyonla $4 \mathrm{~mm}$ kalınlığa kadar tek tabaka (bulk, kütle) halinde yerleştirmeye izin vermektedir. ${ }^{11}$ Tek tabakalı olarak uygulanmasıyla klinik çalışma süresini kısaltarak zaman tasarrufu sağladığı ve hasta-hekim konforunu artırdığı bilinmektedir. ${ }^{9,10}$ Zaman tasarrufunun yanı sıra, tabakalama tekniğinde ortaya çıkabilecek tabakalar arasında nem kontaminasyonu ve boşluk kalma riskini de ortadan kaldırarak daha kompakt restorasyonlar elde edilmesini sağlar. ${ }^{12}$

Restoratif materyallerdeki devamlı gelişmelere karşın dental restorasyonlar temel olarak sekonder çürük ve marjinal kırığa bağlı olarak başarısızlığa uğrarlar. Değiştirmenin yanı sıra başarısız restorasyonların tedavisinde hasarlı restorasyonu tamir eden daha konservatif bir yaklaşım önerilmiştir. ${ }^{13}$ Diş-restorasyon ara yüzündeki küçük çürük ve lekeli lezyonların ekskavasyonundan sonra karyojenik bakterilerin bulunması rekürrent çürüğü ve bunu takip eden tamir prosedürü başarısızlığını belirleyebilir. Bu nedenle tamir bölgesinin ilave dezenfeksiyon yöntemleri göz önünde bulundurulmalıdır. ${ }^{14,15}$

Klorheksidin en popüler antimikrobiyal solüsyon ve matriks metalloproteinaz (MMP) inhibitörüdür. Klorheksidin üzerine yapılan çalışmalarda diğer dezenfektanlarla karşılaştııılı̆ğında klorheksidin daha iyi antimikrobiyal aktivite göstermiştir. ${ }^{16}$ Çoğu çalışma klorheksidinin streptococcus mutans sayısını önemli ölçüde azalttığını bildirmiştir. ${ }^{17-19}$ Klorheksidinin \% 2'lik çözeltisi sitoplazmik içerikleri çöktürerek ve hücre ölümüne yol açarak bakterisidal etki gösterir. ${ }^{20}$

Klorheksidin dental uygulamalarda antimikrobiyal aktivitesi nedeniyle tanıtılmış ve bonding prosedürleri öncesi kavite dezenfektanı olarak kullanılması önerilmiştir. Bu nedenle tamir bölgesi de bakteriyal invazyona maruz kaldığından dezenfeksiyonu için klorheksidin uygulaması önerilebilir. Yine de metakrilat bazlı restoratif materyallerin tamiri öncesi klorheksidin uygulanması ile ilgili bazı kaygılar da bulunmaktadır. ${ }^{21}$

Termal siklus, restorasyon materyallerinin ağız içinde maruz kaldığı durumları laboratuvar ortamına yansıtmak amacıyla kullanılan bir yaşlandırma yöntemidir. Bu test aşırı derece sıcaklıklara maruz kalan örnekleri kapsar. Rosales ve ark. ${ }^{22}$ termal siklus uygulamasının kolay uygulanabilir bir yöntem olduğunu ve klinikte oluşabilecek en yüksek ve en düşük ısısal stresleri diş ve kullanılan materyallere uyguladığını bildirmişlerdir. Sıcaklık değerleri, bekleme zamanı ve devir sayısını da içeren çeşitli faktörler termal siklusun adeziv sistemler üzerindeki bağlanma kuvvetini etkiler. Devir sayısının tüm bunlar arasında en etkili faktör olduğu düşünülür. ${ }^{23} \mathrm{Bu}$ çalışmanın amacı nanofil ve bulk-fill kompozitlerin tamir sonrası makaslama bağlanma dayanımları üzerine klorheksidin ve termal siklus uygulamasının etkisini değerlendirmek ve örnek yüzeylerini SEM görüntüleri ile incelemektir. Sıfır hipotezi klorheksidin uygulamasının iki kompozitinde tamir bağlanma dayanımını etkilemeyeceğidir.

\section{GEREÇ VE YÖNTEM}

\section{Makaslama örneklerinin hazırlanması}

Kullanılan materyaller, içerikleri üretici firma detayları Tablo-1; deney gruplarının ve alt grupların dağılımı Şekil-1'de gösterilmiştir.

$20 \mathrm{~mm}$ uzunluk ve $15 \mathrm{~mm}$ çapındaki metalik kalıplar kullanılarak 160 adet silindir şeklinde akrilik blok hazırlandı. Metalik bir frezle her bir metakrilat silindirin serbest yüzeyine $2 \mathrm{~mm}$ derinlik ve $6 \mathrm{~mm}$ çapında silindirik kaviteler açıldı. Kavitelerin yarısı bulk-fill restoratif materyal (Tetric EvoCeram Bulk Fill, IvoclarVivadent Schaan, Liechtenstein), diğer yarısı ise nanofil kompozitle (Filtek Ultimate Universal Restoratif, 3M ESPE, St. Paul, MN, USA) ile dolduruldu $(\mathrm{N}=80)$. Çalışma boyunca $1200 \mathrm{~mW} / \mathrm{cm}^{2}$ çıkış şiddetindeki aynı led cihaz kullanıldı (Elipar S10, 3M ESPE, St. Paul, MN, USA). Bütün örnekler 1 hafta $37^{\circ} \mathrm{C}$ distile suda bekletildikten sonra restore edilen kavitelerin serbest yüzü 400 grenli silikon karpit kağıt zımpara ile elmas frez ile benzer yüzey pürüzlülüğü elde etmek için aşındırıldı ve yıkanıp kurutulduktan sonra örnekler 2 deneysel gruba ayrıldı $(n=40)$.

Grup1: Örnekler 60 saniye klorheksidin uygulamasına maruz bırakıldı (Cavity Cleanser ${ }^{\mathrm{TM}}$, Bisco, Schaumburg, II, Usa). Uygulama sonrasında örnekler 15 saniye hava spreyi ile kurutuldu.

Grup 2: Herhangi bir uygulama yapılmadı. (kontrol grubu) 
Tablo 1.

\section{Çalışmada kullanılan materyaller, üretici bilgileri ve bileşimleri}

\begin{tabular}{|c|c|}
\hline Materyal, tipi ve üretici & İçeriği \\
\hline $\begin{array}{l}\text { Filtek Ultimate Universal (FU) } \\
\text { Nanofil Kompozit } \\
\text { (3M ESPE, St. Paul, MN, USA) }\end{array}$ & $\begin{array}{l}\text { Bisfenol A-Glisidil Metakrilat (Bis- } \\
\text { GMA), Üretan } \\
\text { dimetakrilat(UDMA), Trietilen } \\
\text { glikol dimetakrilat (TEGDMA), } \\
\text { polietilen glikol } \\
\text { dimetakrilat(PEGDMA), } \\
\text { ethoxylated bisphenol-A } \\
\text { dimethacrylate (Bis-EMA), } 20 \text { nm } \\
\text { silika partikülleri, } 4 \text {-11 nm } \\
\text { zirkonyum partikülleri (78.5 \% } \\
\text { ağırlıkça -63.3\%hacimsel } \\
\text { doldurucu) }\end{array}$ \\
\hline $\begin{array}{l}\text { Tetric EvoCeram Bulk Fill (TEBF) } \\
\text { Bulk fill kompozit } \\
\text { (Ivoclar-Vivadent, Schaan, Liechtenstein) }\end{array}$ & $\begin{array}{l}\text { Bisfenol A-Glisidil Metakrilat (Bis- } \\
\text { GMA), Üretan } \\
\text { dimetakrilat(UDMA). Ba-AI-Si-cam } \\
\text { partikülleri, prepolimer } \\
\text { doldurucular (monomer, glass } \\
\text { filler and iterbium fluorid), } \\
\text { doldurucu \% 79-81 ağırlıkça / \% } \\
60-61 \text { hacimsel }\end{array}$ \\
\hline $\begin{array}{l}\text { Single Bond Universal } \\
\text { Universal Adeziv } \\
\text { (3M ESPE, St. Paul, MN, USA) }\end{array}$ & $\begin{array}{l}\text { Bis-GMA, MDP, dimetakrilat } \\
\text { rezinleri, HEMA, Vitrebond } \\
\text { kopolimer, silan, etanol, su }\end{array}$ \\
\hline $\begin{array}{l}\text { ExciTE F } \\
\text { Total Etch Adeziv Sistemi } \\
\text { (Ivoclar-Vivadent Schaan, Liechtenstein) }\end{array}$ & $\begin{array}{l}\text { Phosphonic asit akrilat, HEMA, } \\
\text { dimetakrilat, yüksek dağılımlı } \\
\text { silikon dioksit, iniyatörler, } \\
\text { stabilizer, potasyum fluorid }\end{array}$ \\
\hline $\begin{array}{l}\text { Cavity Cleanser }{ }^{\mathrm{TM}}, \quad \text { (CHX) } \\
\text { (Bisco, Schaumburg, II, Usa). }\end{array}$ & $\begin{array}{l}\% \text { 2'lik klorheksidin diglukonat } \\
\text { çözeltisi }\end{array}$ \\
\hline
\end{tabular}

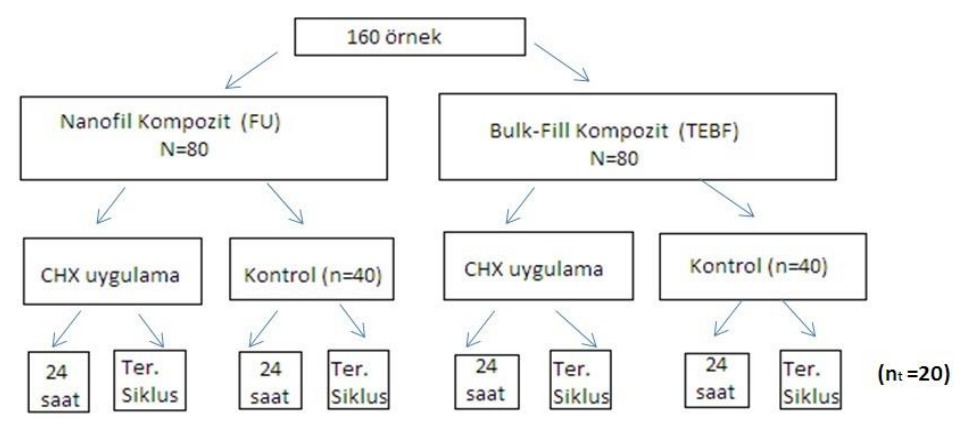

Şekil 1.

Deney grupları ve alt grupların dağılımı

Daha sonra hem klorheksidin uygulanan grubun hem de kontrol grubunun yarısına restorasyonlarına uygun adeziv sistem ara tamir ajanı olarak uygulandı. Nanofil grubuna Single Bond Universal Adeziv (3M ESPE, St. Paul, MN, USA), bulk-fill grubuna ise ExciTE $F$ Universal adeziv (IvoclarVivadent Schaan, Liechtenstein) kullanıldı
Adeziv uygulamasını takiben $3 \mathrm{~mm}$ çapında $4 \mathrm{~mm}$ uzunluğunda silikon aracılığı ile her örnek kendi kompoziti ile tamir edildi. Tamir sırasında nanofil kompozit $2 \mathrm{~mm}$ tabakalar halinde, bulk fill kompozit ise $4 \mathrm{~mm}$ tek tabaka halinde yerleştirildi. Tamir işleminden sonra her örnek $37^{\circ} \mathrm{C}$ suda 24 saat bekletildi. Daha sonra her gruptaki örneklerin yarısına test öncesi 5000 termal siklus (Gökçeler Makine, Sivas,Türkiye) uygulandı $(\mathrm{nt}=20)$. (suda sıcaklık 5-55 ${ }^{\circ} \mathrm{C}$ arası, bekletme zamanı 30 saniye, değişim zamanı 15 saniye), diğer yarısı ise hemen makaslama bağlanma testi işlemlerine alındı.

\section{Makaslama bağlanma testi}

Direkt işleme alınan ve siklusdan çıkan tamir örnekleri üniversal test makinesine (LF Plus, LLOYD Instruments, Ametek Inc., England) konuldu ve kopma oluşana dek 0.5 $\mathrm{mm} /$ dakika hızla makaslama testi uygulanarak tamir bağlanma dayanımı test edildi. Kopmadaki yük (N) bağlanma alanına bölünerek (mm2) makaslama bağlanma dayanımı megapaskal (MPa) olarak ifade edildi. Kırık örnekler 2.5 büyütmelik optik lupta incelenmiş ve kopma tipleri aşağıdaki gibi sınıflandırılmıştır:

$\operatorname{Adeziv(AK):~Kopma~adeziv~yüzey~yani~eski~}$ materyal ile tamir materyali ara yüzünde.

Dolguda koheziv (DK): Kopma akrilik bloktaki restoratif materyalde.

Tamirde koheziv(TK): Kopma tamir materyalinde.

Karışık (KK): Yukarıda tarif edilen modellerden 2 veya daha fazlası kombine olduğunda.

\section{İstatistiksel Değerlendirme}

Makaslama kuvveti veri dağılımı normalitesi ve deney grupları arasındaki varyans homojenliği doğrulandı (Kolmogorov Simirnov Test ve Levene Testi). Her restoratif materyaldeki makaslama bağlanma dayanımı analizi için ana faktör olarak test öncesi termal döngü ile klorheksidin kullanımı baz alınarak çift yönlü varyans analizi kullanımıştır. Windows için SPSS 16.0 kullanılmıştır. Önemlilik seviyesi $\mathrm{p}<0.05$ alınmıştır. 


\section{BULGULAR}

Gruplara ait bağlanma dayanımı değerleri Tablo-2'de gösterilmiştir. Klorheksidin ve termal siklus uygulaması tamir bağlanma dayanımını istatistiksel olarak anlamlı bir şekilde etkilememiştir. İki uygulamanın etkileşimi de bağlanma dayanımı üzerine istatistiksel olarak anlamlı bir etkide bulunmamıştır.

Bulk-fill kompozitler sayısal olarak daha düşük tamir bağlanma dayanımı göstermiştir. Tamir bağlanma değerleri Bulk-fill (Tetric EvoCeram) kompozitlerde $27.81 \mathrm{MPa}$ ve 28.45 MPa arasında değişirken, Nanofil (Filtek Ultimate) kompozitlerde $30.61 \mathrm{MPa}$ ile $35.24 \mathrm{MPa}$ arasında değişmektedir (Tablo 2). En yüksek sayısal bağlanma değeri Nanofil kompozitlerle 24 saat sonra kontrol grubunda elde edilirken en düşük değer klorheksidin uygulaması sonrası termal siklus yapılan bulk-fill kompozitlerde bulunmuştur. Nanofil kompozit ile bulk fill kompozitin bağlanma dayanımı değerleri gruplar arasında farklılık gösterse de; bu fark istatistiksel olarak anlamlı değildir.

Mix tip kırılmalar en fazla rastlanan tip kırılmalar olmuştur. Orjinal dolguda ise koheziv kırılmalar ikinci fazla görülen kırılmadır. Adeziv kırılma ve tamir kompozitinde koheziv kırımaya ise daha az rastlanmıştır (Tablo-3). Deney gruplarından elde edilen kırıma tiplerinin SEM görüntüleri Resim 1'de gösterilmiştir.

\section{Tablo 2.}

\section{Gruplara ait tamir bağlanma dayanımı değerleri}

\begin{tabular}{|lcccc|} 
Grup & \multicolumn{2}{c}{ Nanofil Kompozit (FU) } & \multicolumn{2}{c|}{ Bulk-fill kompozit (TEBF) } \\
\cline { 2 - 5 } & 24 saat & $\begin{array}{c}\text { Termal } \\
\text { Siklus }\end{array}$ & 24 saat & $\begin{array}{c}\text { Termal } \\
\text { siklus }\end{array}$ \\
\hline Klorheksidin & $30.61(5.9)^{\mathrm{A}, a}$ & $30.11(5.5)^{\mathrm{A}, \mathrm{a}}$ & $27.81(4.3)^{\mathrm{A}, \mathrm{a}}$ & $27.35(4.4)^{\mathrm{A}, \mathrm{a}}$ \\
\hline Kontrol & $35.24(6.4)^{\mathrm{A}, \mathrm{a}}$ & $34.04(5.5)^{\mathrm{A}, \mathrm{a}}$ & $28.45(3.7)^{\mathrm{A}, \mathrm{a}}$ & $27.85(3.9)^{\mathrm{A}, \mathrm{a}}$ \\
\hline & $\mathrm{f}=1.864$ & $\mathrm{p}=0.153$ & $\mathrm{p}>0.05$ & \\
\hline
\end{tabular}

*üst simgeler gruplar arasındaki istatistiksel ilişkiyi göstermektedir. Büyük harfler sütun küçük harfler satırlar arasındaki farklıı̆ı ifade etmektedir
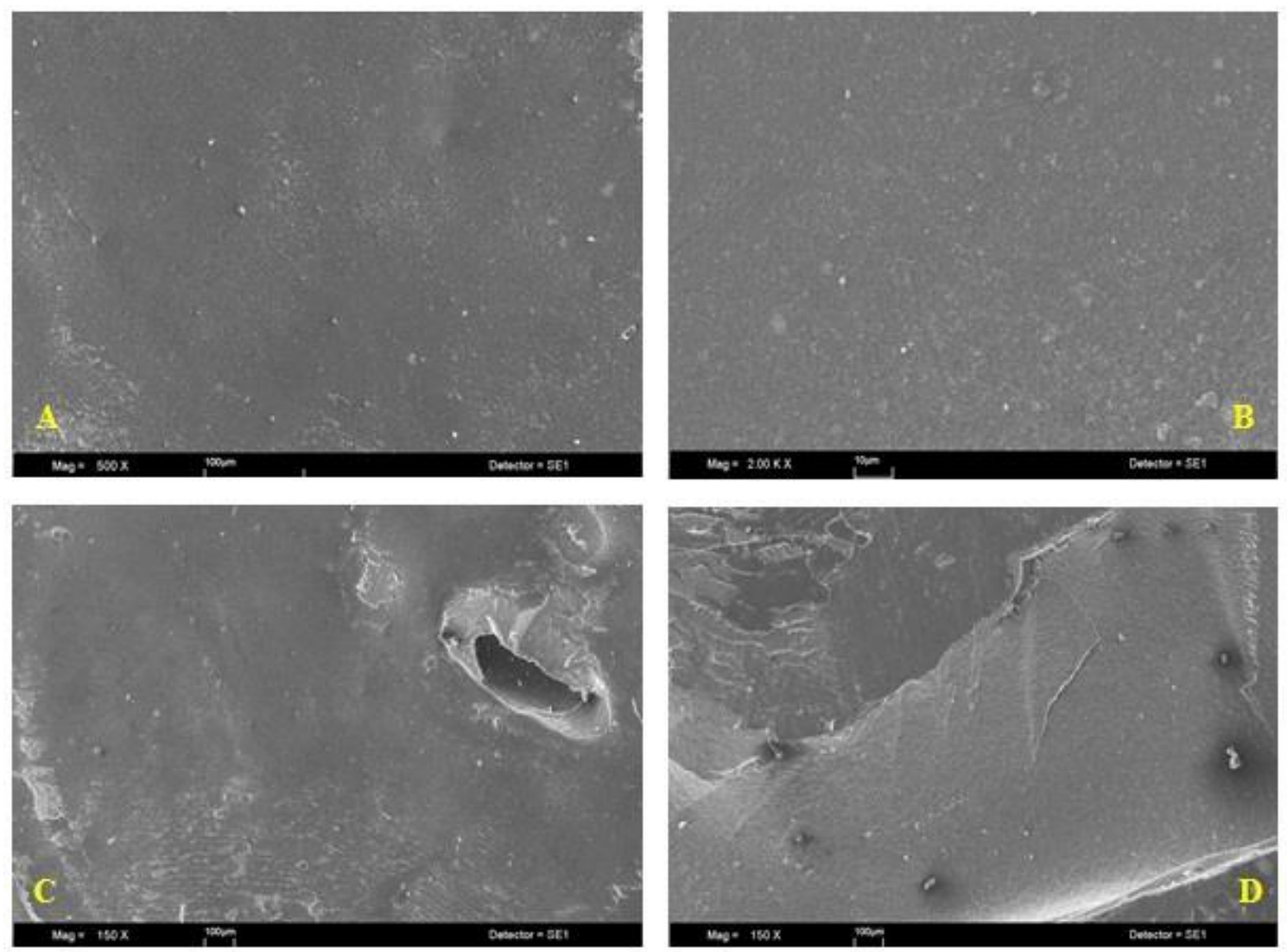

Resim 1.

Kırılma tiplerinin SEM görüntüleri

A) Nanofil kompozitte görülen adeziv kırılmaya ait SEM görüntüsü

B) Klorheksidin uygulanmış bulk-fill kompozitte görülen adeziv kırılmaya ait SEM görüntüsü

C) Nanofil kompozit tamir materyalinde görülen koheziv tip kırılmaya ait SEM görüntüsü

D) Klorheksidin uygulanmış bulk-fill kompozitte görülen karışık tip kırılmaya ait SEM görüntüsü 
Tablo 3.

\section{Kırılma tipleri dağılımı}

\begin{tabular}{|c|c|c|c|c|c|}
\hline & Gruplar & Adeziv & $\begin{array}{l}\text { Tamirde } \\
\text { koheziv }\end{array}$ & $\begin{array}{c}\text { Restorasyonda } \\
\text { koheziv }\end{array}$ & $\begin{array}{c}\text { Karışık } \\
\text { tip }\end{array}$ \\
\hline \multirow{2}{*}{$\begin{array}{l}\text { Nanofil } \\
\text { (FU) Kontrol }\end{array}$} & 24 saat & 1 & 2 & 7 & 10 \\
\hline & Ter. Siklus & 3 & 2 & 5 & 10 \\
\hline \multirow{2}{*}{$\begin{array}{l}\text { Nanofil } \\
\text { (FU) CHX }\end{array}$} & 24 saat & 2 & 3 & 7 & 8 \\
\hline & Ter. Siklus & 3 & 4 & 6 & 7 \\
\hline \multirow{2}{*}{$\begin{array}{l}\text { Bulkfill } \\
\text { (TEBF) } \\
\text { Kontrol }\end{array}$} & 24 saat & 3 & 3 & 5 & 9 \\
\hline & Ter. Siklus & 4 & 4 & 5 & 7 \\
\hline \multirow{2}{*}{$\begin{array}{l}\text { Bulkfill } \\
\text { (TEBF) CHX }\end{array}$} & 24 saat & 2 & 3 & 7 & 8 \\
\hline & Ter. Siklus & 4 & 2 & 6 & 8 \\
\hline
\end{tabular}

\section{TARTIŞMA}

Kompozit-kompozit tamir bağlanma dayanımı tamir materyali ile restorasyon arasındaki adezyona bağlıdır. Uygulanan yüzey işlemleri, yaşlandırma metodları ve kompozitlerin tipi bu adeziv bağlantıyı etkileyebilir. Çalışmadan elde edilen veriler klorheksidin uygulamasının bulk-fill kompozit ve nanofil kompozitin tamir dayanımını etkilemediğini göstermiştir. Böylece test edilen sıfır hipotezi kabul edilmiştir.

Sekonder çürük oluşumu hasarlı bir dolgunun değiştirilmesi için ana sebeptir. ${ }^{24}$ Fakat restorasyonun tamamen sökülmesi yerine tamiri hem maliyet hem zaman tasarrufu sağlamasının yanında geriye kalan sağlam dokunun da korunmasını sağlar. Restorasyon kenarlarında sekonder çürük varlığında, diş dolgu ara yüzünde açılacak bir tanı kavitesi restorasyonun tamamen kaldırımadan çürüğün boyutlarının tayininde bize yardımcı olabilir. Ve sağlam doku etkilendiyse bu tanı kavitesi geleneksel restoratif tekniklerle tamir edilebilir. ${ }^{25}$

Eğer minimal düzeyde çürük temizleme işlemi yapıldıysa, ek olarak kavite dezenfektanlarının kullanılması, patolojik bakterilerin kavitede devamını engeller. ${ }^{26}$ Tamirde oluşabilecek hatalarında önüne geçilebilir. Bunun yanında kullanılacak dezenfektan diş dokuları ve restoratif materyalle, yeni yapılan restorasyonun bağlanmasını olumsuz yönde etkilememelidir. $\mathrm{Bu}$ çalışma klorheksidin uygulamasının iki değişik restoratif materyalle yapılan tamirdeki bağlanma dayanımına etkisini incelemiştir.

Çalışmamızda klorheksidinin kompozit-kompozit tamir bağlanma dayanımı üzerine etkisine bakılmıştır. Çoğu çalışma klorheksidin uygulaması sonrası restoratif materyalin dentine bağlanma dayanımı üzerinedir. Bu çalışmaların çoğunda bizim çalışmamı ile uyumlu olarak klorheksidinin bağlanma dayanımını etkilemediği sonucuna varılmıştır. ${ }^{27,28}$ Bununla birlikte bir çalışmada klorheksidin uygulanmış dentin yüzeyinde oluşan klor iyonları ve kristal şeklindeki çökeltilerin bağlanma dayanımını olumsuz etkilediğini bildirmiştir. ${ }^{29}$

Çalışmada iki güncel restoratif materyal ve bunlara uygun bağlayıcı ajanlar kullanılmıştır (Tetric EvoCeram Bulk Fill ve
Filtek Ultimate). Bulk fill materyaller tabakalar halinde yerleştirme yöntemiyle kullanılan kompozitlerde gözlenen birtakım sorunları ortadan kaldırmaktadır. Düşük polimerizasyon büzülmesiyle dişteki deformasyon, postoperatif hassasiyet, mikrosızıntı ve ikincil çürük olasılığını azalttığı bildirilmiştir. , $^{9,30}$

Nanofil kompozitler yapılan çalışmalarda geleneksel kompozitlere laboratuvar ve klinik olarak benzer özellikler göstermiştir. ${ }^{31,32}$ Bizim çalışmamızda nanofil kompozit olan Filtek Ultimate ve uygun adezivi kullanılmıştır. Çalışmanın amacı kullanılan iki restoratif materyali karşılaştırmak olmasa da nanofil kompozitle (FU) yapılan tamirde elde edilen tamir bağlanma dayanımı daha önceki bir çalışma ile uyumlu olarak, bulk-fill kompozite (TEBF) göre istatistiksel olarak anlamlı olmasa da daha yüksek bulunmuştur. ${ }^{33}$ Yine daha önce başka bir nanofil kompozit (Filtek Supreme XT) ile yapılan bir çalışmada yaşlandırma sonrası mikrogerilim bağlanma dayanımları bulk fill (TEBF) kompozitten daha yüksek bulunmuştur. ${ }^{34} \mathrm{Bu}$ durum kompozitlerin içeriğindeki monomer dağılımı ve içerdikleri monomerlerin farklılığından kaynaklanabilir. Kompozitlerde bulunan monomerler çeşit ve bağlanmanın rijiditesi bakımından su absorbsiyonunu etkileyerek doğrudan bağlanma dayanımını etkileyebilmektedir.35,36 Ayrıca uygulanan adeziv sistemin de tamir bağlanma dayanımını etkilediğini gösteren çalışmalarda vardır. ${ }^{37,38}$

Örneklerdeki mix ve koheziv kırılmaların adeziv kırılmadan fazla olması uygulanan tamir prosedürünün istenen düzeyde iyi bir bağlanma sağladığını göstermektedir. Bu durum yukarıda belirtildiği gibi yapılan restoratif materyalle uyumlu adeziv sistemin seçilmesinden kaynaklanabilir. Ancak hekimler klinikte her zaman tamir edilecek restorasyonu tanımlayamayabilir ve uygun bond seçimini yapamayabilir. Tamir öncesi yapılacak yüzey uygulamalarıda iki kompozit arasındaki bağlanmayı artırabilir. ${ }^{15}$ Çalışmamızda restoratif materyalin yüzeyi frezle yüzey hazırlama sonrası oluşan pürüzlülüğe benzer bir pürüzlülük elde etmek amacıyla 400 grenlik silikon karbit kağıt zımpara ile aşındırılmıştır.

Termal siklus, çevre sıcaklık değişikliklerini simule etmek için örneklerde sık kullanılan bir yöntemdir. Yaşlandırma teknikleri kullanılan kompozitlerde zamanla aşınma, enzimatik çözülme ve matriks organizasyonunda 
bozulma gibi fiziksel ve kimyasal değişiklikler oluşur. ${ }^{35}$ Önceki bir çalışmada Papacchini ve ark. ${ }^{39}$ değişik kompozit tamir prosedürlerini termal siklus sonrası incelemiş ve bağlanma dayanımında belirgin bir düşüş saptamıştır. Bizim çalışmamızda termal siklus, bulk-fill ve nanofil kompozitlerin tamir bağlanma dayanımını etkilememiştir. Bu durum döngü sayısı ve uygulanan yöntemin değişiminden kaynaklanabilir.

Yukarıda bahsedilen çalışmaların ışığında; çalışmamızda klorheksidin uygulanmış ve termal siklusa maruz bırakılmış gruplarda elde edilen tamir bağlanma dayanımı değerlerinin klinik olarak kabul edilebilir olduğu söylenebilir. Ancak bulk-fill ve nanofil kompozitlerin tamir bağlanma dayanımlarını geliştirmek için başka çalışmalara da intiyaç vardır.

\section{SONUÇ}

Bu in vitro çalışmanın sınırları dahilinde klorheksidin ve ek olarak uygulanan termal siklus ile yaşlandırma metodu, bulk-fill ve nanofil kompozitlerin tamir bağlanma dayanımını etkilememiştir. Bu yüzden klorheksidin bulk-fill ve nanofil kompozitlerin tamir dayanımını etkilemeksizin; bu tip restorasyonların tamiri sonrasında restorasyon kenarlarında oluşacak sekonder çürükleri önlemek amacıyla klinisyenler tarafından kullanılabilir. 


\section{KAYNAKLAR}

1. Hickel R, Manhart J, Garcia-Godoy F. Clinical results and new developments of direct posterior restorations. Am J Dent 2000; 13: 41D-54D.

2. Manhart J, Garcia-Godoy F, Hickel R. Direct posterior restorations: clinical results and new developments. Dent Clin North Am 2002; 46(2): 303-39.

3. Bayne SC, Heymann HO, Swift EJ, Jr. Update on dental composite restorations. J Am Dent Assoc 1994; 125(6): 687-701.

4. Soncini JA, Maserejian NN, Trachtenberg F, Tavares $M$, Hayes $C$. The longevity of amalgam versus compomer/composite restorations in posterior primary and permanent teeth: findings From the New England Children's Amalgam Trial. J Am Dent Assoc 2007; 138(6): 763-72.

5. Davis N. A nanotechnology composite. Compend Contin Educ Dent 2003; 24: 662-70.

6. Mitra SB, Wu D, Holmes BN. An application of nanotechnology in advanced dental materials. J Am Dent Assoc 2003; 134: 1382-90.

7. Duke ES. Has dentistry moved into the nanotechnology era? Compend Contin Educ Dent 2003; 24: 380-2.

8. Schmidt G, Malwitz M. Properties of polymernanoparticle composites. Curr Opin Coll Int Sci 2003; 8: 103-8.5.

9. Lazarchik DA et al. Hardness comparison of bulkfilled/transtooth and incremental-filled/occlusally irradiated composite resins. The Journal of prosthetic dentistry, 2007. 98(2): 129-140.

10.El-Safty, S., N. Silikas, and D. Watts. Creep deformation of restorative resin-composites intended for bulk-fill placement. Dental Materials, 2012. 28(8): 928-35.

11.El-Damanhoury $\mathrm{H}$ and Platt $\mathrm{J}$. Polymerization shrinkage stress kinetics and related properties of bulk-fill resin composites. Operative dentistry, 2014. 39(4): 374-82.

12.Park $\mathrm{J}$ et al. How should composite be layered to reduce shrinkage stress: incremental or bulk filling? Dental Materials, 2008. 24(11): 1501-05.

13.Mjor IA. Repair versus replacement of failed restorations. Int Dent J 1993; 43(5): 466-72.

14.Dall'Oca S, Papacchini F, Goracci C, Cury AH, Suh $\mathrm{BI}$, Tay FR, et al. Effect of oxygen inhibition on composite repair strength over time. J Biomed Mater Res B Appl Biomater 2007; 81(2): 493-8.

15.Papacchini F, Dall'Oca S, Chieffi N, Goracci C, Sadek FT, Suh BI et al. Composite-to-composite microtensile bond strength in the repair of a microfilled hybrid resin: effect of surface treatment and oxygen inhibition. J Adhes Dent 2007 Feb;9(1): 25-31.
16. Gultz J, Do L, Boylan R, Kaim J, Scherer W. Antimicrobial activity of cavity disinfectants. Gen Dent 1998; 47: 187-90.

17.Kapdan A, Öztaş N, Sümer Z. Comparing the antibacterial activity of gaseous ozone and chlorhexidine solution on a tooth cavity model. J Clin Exp Dent 2013; 5: e133-7.

18.Türkün $M$, Türkün LS, Çelik EU, Ates $M$. Bactericidal effect of $\mathrm{Er}$, Cr: YSGG laser on Streptococcus mutans. Dent Mater J 2006; 25: 81-6.

19. Newbrun E. Preventing dental caries: breaking the chain of transmission. J Am Dent Assoc 1992; 123: 55-9.

20. Gomes BP, Souza SF, Ferraz CC, Teixeira FB, Zaia AA, Valdrighi L, Souza-Filho FJ. Effectiveness of $2 \%$ chlorhexidine gel and calcium hydroxide against Enterococcus faecalis in bovine root dentine in vitro. Int Endod J 2003; 36: 267-75.

21. Li J. Effects of surface properties on bond strength between layers of newly cured dental composites. J Oral Rehabil 1997; 24(5): 35860.12 .

22.Rosales-Leal Jl. Microleakage of Class V composite restorations placed with etch-andrinse and self-etching adhesives before and after thermocycling. Journal of Adhesive Dentistry 2007; 9: 255.

23. Amaral FL, Colucci V, PALMA-DIBB RG, Corona SA. Assessment of in vitro methods used to promote adhesive interface degradation: a critical review. Journal of Esthetic and Restorative Dentistry 2007; 19(6): 340-53

24. Mjor IA, Moorhead JE and Dahl JE. Reasons for replacement of restorations in permanent teeth in general dental practice. Int Dent J, 2000; 50(6): 361-6.

25. Mjor IA and Gordan VV. Failure, repair, refurbishing and longevity of restorations. Oper Dent 2002; 27(5): 528-34.

26. Kidd EA, Ricketts DN and Beighton D. Criteria for caries removal at the enamel-dentine junction: a clinical and microbiological study. Br Dent J 1996; 180: 287-91.

27. de Castro FL, de Andrade MF, Duarte Júnior SL, Vaz LG, Ahid FJ. Effect of $2 \%$ chlorhexidine on microtensile bond strength of composite to dentin. J Adhes Dent 2003; 5: 129- 38.

28. Mobarak EH, El-Korashy DI, Pashley DH. Effect of chlorhexidine concentrations on micro-shear bond strength of self-etch adhesive to normal and caries-affected dentin. Am J Dent 2010; 23: 217-22. 
29. Di Hipólito V, Rodrigues FP, Piveta FB, Azevedo Lda C, Bruschi Alonso RC, Silikas N, Carvalho RM, De Goes MF, Perlatti D'Alpino PH. Effectiveness of self-adhesive luting cements in bonding to chlorhexidine treated dentin. Dent Mater 2012; 28: 495-501

30. Moorthy A, Hogg $\mathrm{CH}$. Dowling AH, Grufferty BF, Benetti AR, Fleming GJ. Cuspal deflection and microleakage in premolar teeth restored with bulk-fill flowable resin-based composite base materials. J Dent 2012; 40: 500-5.

31.llie $\mathrm{N}$ and Hickel $\mathrm{R}$. Investigations on mechanical behaviour of dental composites. Clin Oral Invest 2009; 13(4): 427-38.

32. Bottenberg, $P$ et al. A prospective randomized clinical trial of one bis-GMA-based and two ormocer-based composite restorative systems in class II cavities: Fiveyear results. J Dent 2009; 37(3): 198-203.

33. Vural U, Kerimova L, Baltacioglu iH, Kiremitçi A. Bond strength of dental nanocomposites repaired with a bulkfill composite. J Clin Exp Dent 2017; 9(3): 437-42.

34. Ozcan M, Corazza PH et al. Repair bond strength of microhybrid, nanohybrid and nanofilled resin composites: effect of substrate resin type, surface conditioning and ageing. Clin Oral Invest 2013; 17: 1751-8.

35. Soderholm KJ, Zigan M, Ragan M, Fischlschweiger W, Bergman $M$. Hydrolytic degradation of dental composites. J Dent Res 1984; 63: 1248-54.

36. Bagheri R, Tyas MJ, Burrow MF. Subsurface degradation of resin-based composites. Dent Mater 2007; 23: 944-51.

37. Erdemir A, Eldeniz A, Belli S. Kompozit rezinlerin tamirinde farklı bonding sistemlerin kullanılması. Cumhuriyet Dental Journal 2004; 7(1): 7-10

38.Irmak O. Kompozit reçinelerin farklı adeziv esaslı bağlayıcı ajanlar ile onarımında mikro-makaslama kuvvetlerinin bağlanma dayanımına etkisi. İstanbul Üniv Diş Hek Fak Derg. 2017; 47(1): 17-27

39.Papacchini F, Toledano M, Monticelli F, Osorio R, Radovic I, Polimeni A et al. Hydrolytic stability of composite repair bond. Eur J Oral Sci 2007; 115(5): 417-24.

Yazışma Adresi:

Vahti KILIÇ

FIrat Üniversitesi

Diş Hekimliği Fakültesi

Restoratif Diş Tedavisi AD

23200 Merkez, Elazığ

Tel : +904242370000

GSM : +90 5543071632

E-mail: dt.vahtikilic@gmail.com 